\title{
Studies and Research on the Behavior of Polyethylene when Electrofusion Welding Fittings to High Density Polyethylene Pipes
}

\section{EUGEN AVRIGEAN*}

Lucian Blaga University of Sibiu, Faculty of Engineering, 4 Emil Cioran Str., 550025, Sibiu, Romania

Abstract: This aim of this paper is to perform a study on the way the material of the fittings that can be welded through eletrofusion on polyethylene pipes withstands. The process is observed by means of the thermal and fast cameras. Also we intend to analyze the way the assembly consisting of the polyethylene fitting and pipe behaves during welding. The stresses caused by the welding process are observed, as well as the concurrent welding of the tapping tee and the branch saddle tee.

Keywords: behavior of polyethylene, thermal camera, finite element

\section{Introduction}

The materials used for producing plastics are natural materials, for example cellulose, resins, oil or natural gas. The most important raw materials used for this purpose are oil and natural gas. Crude oil is separated by distillation into fractions. The temperatures at which the materials reach the boiling stage give the different degrees of distillation: gas, black oil, gasoline, kerosene, and bitumen as residue. All these contain hydrocarbons differing in terms of the size and configuration of the molecules. The most important fraction for producing plastics is straight-run distillation gasoline. This is further divided by a process employing thermal cracking and called vapor cracking, creating several types of hydrocarbons such as ethylene, propylene, butylene [1, 4, 5].

We can therefore say that the plastic materials are obtained by chemically transforming natural products, or synthetically changing them, starting from organic compounds, mainly containing carbon (C) and hydrogen $(\mathrm{H})$. Most plastic materials are made of hydrocarbons which create distinct combinations of plastics, called monomers, which are actually same type monomer molecules $[1,4,6]$.

Main characteristics of polyethylene PE 100, used in the manufacture of high density polyethylene pipes (Table 1) [7, 11].

Table 1

\begin{tabular}{|c|c|c|c|}
\hline Physical characteristics & Method & UM & values \\
\hline Density at $23^{\circ} \mathrm{C}$ & ISO 1183 & $\mathrm{Kg} / \mathrm{m}^{3}$ & $958 \div 960$ \\
\hline $\begin{array}{l}\text { Fluidity index MRF } \\
\text { (5kg/190degrees) }\end{array}$ & ISO 1133 & $\mathrm{~g} / 10 \mathrm{~min}$ & $0.2 \div 0.4$ \\
\hline Mechanical characteristics & Method & UM & Values \\
\hline $\begin{array}{c}\text { Tensile strength at } 23^{\circ} \mathrm{C} \text { at } 50 \\
\mathrm{~mm} / \mathrm{min}\end{array}$ & ISO 527 & $\mathrm{MPa}$ & $23 \div 25$ \\
\hline at $100 \mathrm{~mm} / \mathrm{min}$ & ISO 527 & $\mathrm{MPa}$ & $24 \div 26$ \\
\hline $\begin{array}{c}\text { Fracture strength at } 23^{\circ} \mathrm{C} \\
\text { at } 100 \mathrm{~mm} / \mathrm{min}\end{array}$ & ISO 527 & $\mathrm{MPa}$ & $30 \div 36$ \\
\hline $\begin{array}{l}\text { Fracture elongation at } 23^{\circ} \mathrm{C} \text { at } 50 \\
\mathrm{~mm} / \mathrm{min}\end{array}$ & ISO 527 & $\%$ & $>350 \%$ \\
\hline at $100 \mathrm{~mm} / \mathrm{min}$ & ISO 527 & $\%$ & $>600 \%$ \\
\hline Tensile elastic modulus at $23^{\circ} \mathrm{C}$ & ISO 527 & $\mathrm{MPa}$ & $900 \div 1100$ \\
\hline Thermal characteristics & Method & UM & Values \\
\hline $\begin{array}{c}\text { Average coefficient of } \\
\text { linear thermal expansion }\end{array}$ & ASTM D696 & $\mathrm{K}^{-1}$ & $2.0 \times 10^{-4}$ \\
\hline
\end{tabular}

\footnotetext{
*email:eugen.avrigean@ulbsibiu.ro
} 


\section{Materials and methods}

\subsection{The Importance of conducting the research on the suggested topic [1]}

After studying the literature on the behavior of polyethylene, it was found that the main defects identified in the welds performed on pipes are the following: the assemblies are not linear; the welds are incomplete; the control is not expelled; the molten material is expelled outwards or inwards; the coils are broken or short-circuited; the ends are oval; the device is unable to complete the welding cycle; the T-branch socket leaks, etc.

Thus, a need emerged to conduct a study on how polyethylene behaves during and after the welding process, to identify the negative factors in the process, as well as to find the best solutions to eliminate or avoid them [2].

\subsection{Electrofusion welding the branch tee to the polyethylene pipe}

Welding the tapping tee fixed on the polyethylene pipe-the procedure is based on welding a part called the electrofitting (Figure 2). It is composed of the body, made by injection from high density polyethylene, in several geometric shapes according to the design of the assembly (joints, branches, diameter change, etc.). The electrofitting has an in-built electrical resistance, welding indicators and electrical connectors which link it to the welding machine. The areas that will be welded (the outer side of the pipe and the inner side of the electrofitting) heat up to the plasticization temperature, because of the electrical resistance imbedded in the interior of the electrofitting. When heating the pipe-fitting assembly, the material expands until it reaches a size which has been calculated beforehand by taking into consideration the distance between the two parts and then, when it reaches the temperature of about $220^{\circ} \mathrm{C}$, a molten homogenous mass is formed. The electric current is cut in the electric resistance and the process of solidification of the molten mass begins, thus welding the two surfaces in contact (Figure $1)$.

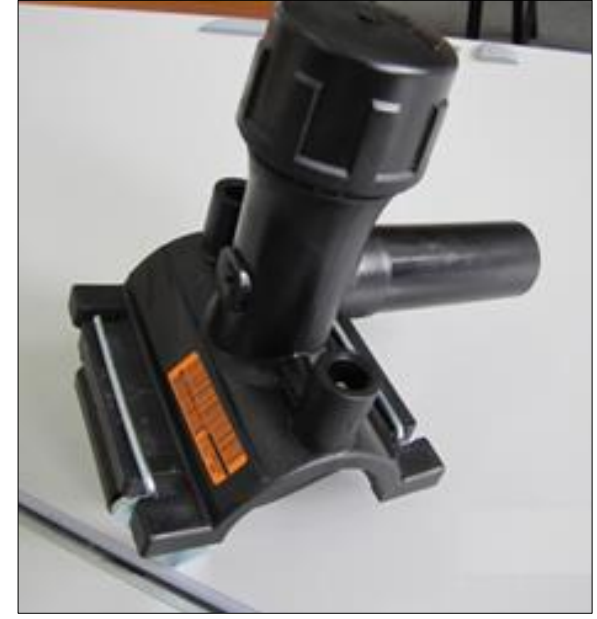

Figure 1. Tapping tee

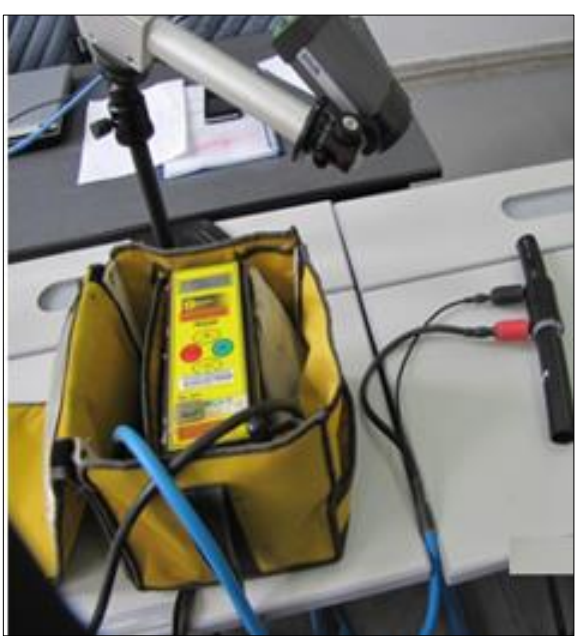

Figure 2. Polyethylene electrofusion welding machine

The welding machine, through its control processor, automatically monitors and registers the welding measurements and the intensity of the current which are required for plasticizing the contact surfaces. The intensity of the current flowing through the coil of the electrofitting is determined with the relation I-U/R where: $\mathrm{I}$ is the intensity of the current, $[A] ; U$ is the voltage in the welding terminals $[\mathrm{V}]$ and $\mathrm{R}$ is the electrical resistance, $[\mathrm{Ohm}]$.

The first parts of the fitting that are heated are its ends, then the heat spreading towards the inner part as well. The solidified molten mass will not leak outside the welded area. It is possible to electrofusion weld only the same type of material. The melt flow index of the electro-sockets has a value from 0.7 and $1.3 \mathrm{~g} / 10 \mathrm{~min}$. It is possible to weld pipes and fittings with a melt flow index varying between 0.4 and 
$1.3 \mathrm{~g} / 10 \mathrm{~min}$. The electro fusion fitting is provided with a bar code which indicates the parameters of the welding. Sometimes, a magnetic card is supplied with the electro fitting which should be inserted into the soldering machine. Upon completion of the welding, the technical information on how to set the welding parameters contained in the card are deleted, which means it is possible to use the card a single time. All the joints prepared for welding will be mounted without being stressed. The pipes are not allowed to be loose inside the fittings or to be bent. After mounting the electro-fittings, we must check whether it is possible to easily twist them (without considerable effort). For the electrofusion welding we used the SBox polyethylene welding machine from Fusion Romania company, operated by authorized gas installers and polyethylene welders employed by companies authorized in the field, under the supervision of the welding technical manager within the company. Figure 3 shows an electrofusion branch tee of 90-63 mm diameter.

The analysis of the welding process led to the conclusion that $80 \mathrm{~s}$ are required for welding this fitting, while it takes it at least 12 min to cool down.

\section{Welding saddle tees with the G-clamp}

The same welding and cooling times were taken into consideration when executing such welds, but the difference between the two types of tees will be noticeable in terms of stress. The welding machine used is the same and the characteristics are the one presented above.

The device used for fixing a saddle tee has the following characteristics:

- It can fix tees and saddles on the pipe up to 630mm;

- It is made of anticorrosive materials;

- It has a pressure indicator for a correct pressing;

- It can be used at temperatures from -5 to +40 degrees [12].

\section{Results and discussions}

\subsection{Three-dimensional modeling of the polyethylene fitting- pipe assembly}

The part was geometrically modeled in Catia software, where there is a module which uses the finite element method, therefore eliminating the risk of the plausible discrepancies between the files created with Catia or with other finite element software [8].

The CIM (Computer Integrated Manufacturing) systems included a CAE (Computer Aided Engineering) Module when the CAD (Computer Aided Design) module was developed. The finite element method emerged at the same time. This method was initially employed for mechanically calculating the structures of aircraft but later it was also used for other problems of the continuum mechanics. In order to solve these problems, it is required to determine the values of one or more unknown functions measured on a specific area, such as: momentums, displacements, thermal readings, stresses, strains, etc., according to the studied problem [8].

Differential equations help explain natural phenomena like this. The exact solution is reached when we subject them to certain boundary constraints. Thus, the unknown function or functions can be calculated in any point on the area subjected to research. This method to solve a problem is analytical and it applies to rather simple matters. On the other hand, the problems that occur in practice are far from simple. They are comprehensive from the point of view of the way the part is geometrically constructed and of the constraints applied when it is stressed. In such a case, it is no longer possible to solve the differential equations, but one of the following solutions will be applied:

- We create a simplified model and we solve the differential equations on it. We will reach the exact solution on this simplified model;

- We can obtain an approximate solution to a real problem.

For explanatory reasons, we selected the following models: a tapping tee Dn 63 per 32 in diameter and a saddle tee Dn 63 per 32 in diameter (Figure 5 to 13) which were three-dimensionally modeled and considered welded by means of the G-clamp (the tapping tees, Figures 14 to 20) and a clamp, so that the following values of Von Mises stresses and displacements were obtained, as presented below [9]. 


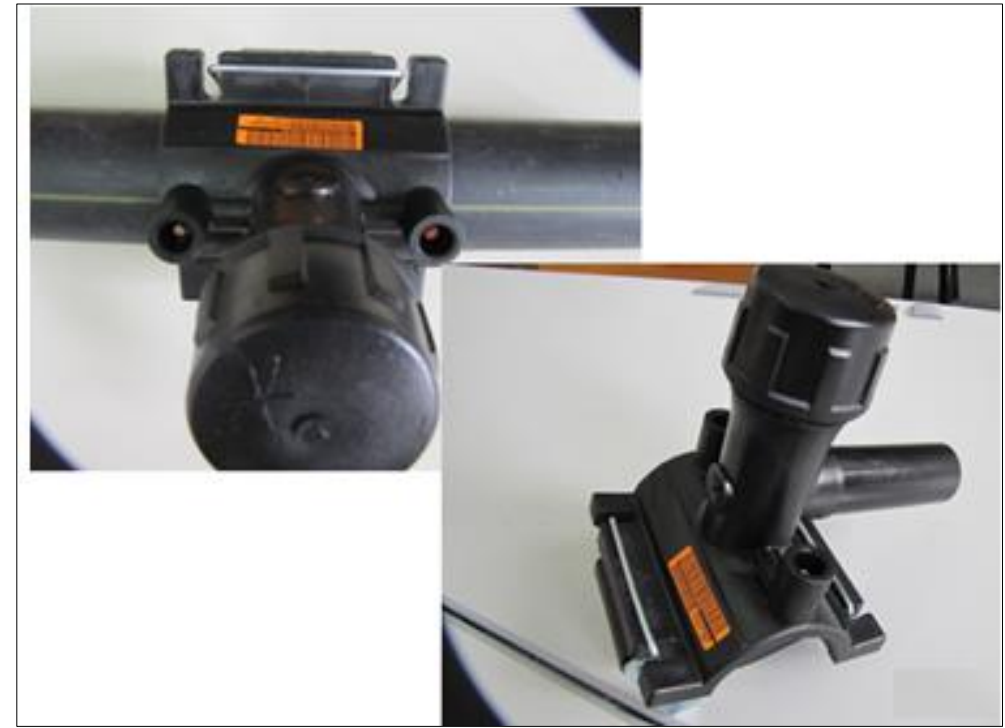

Figure 3. Polyethylene fitting 63-32 $\mathrm{mm}$ in diameter, before and after welding

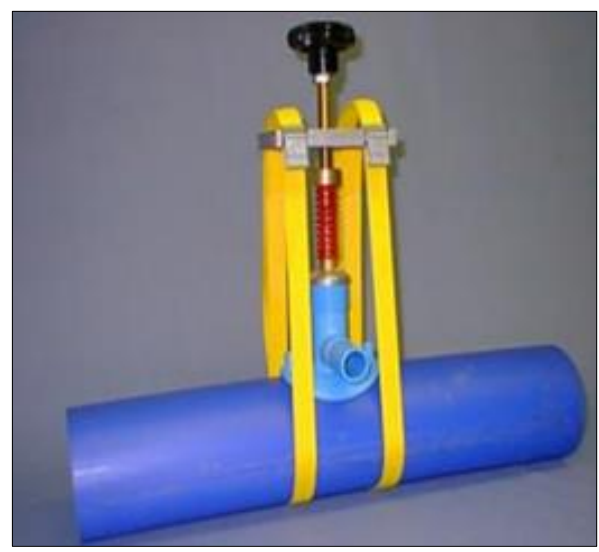

Figure 4. Device for fixing a saddle tee [12]

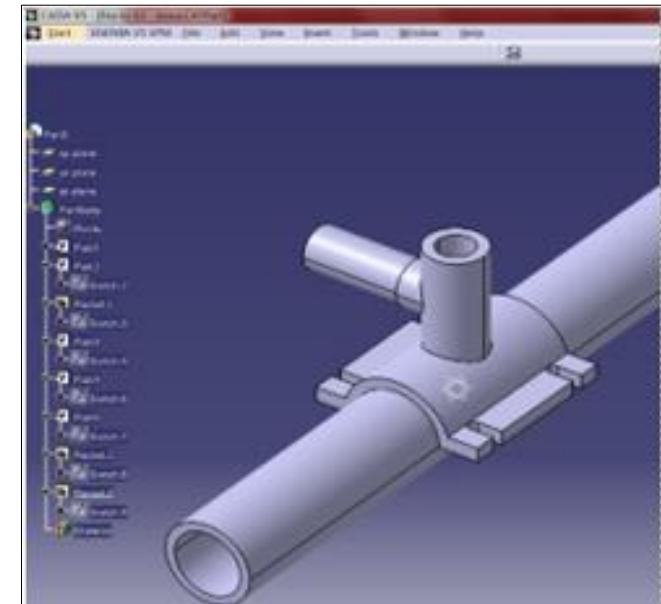

Figure 5. Designing the 3D model of the branch saddle tee mounted on a polyethylene pipe, by means of Catia software

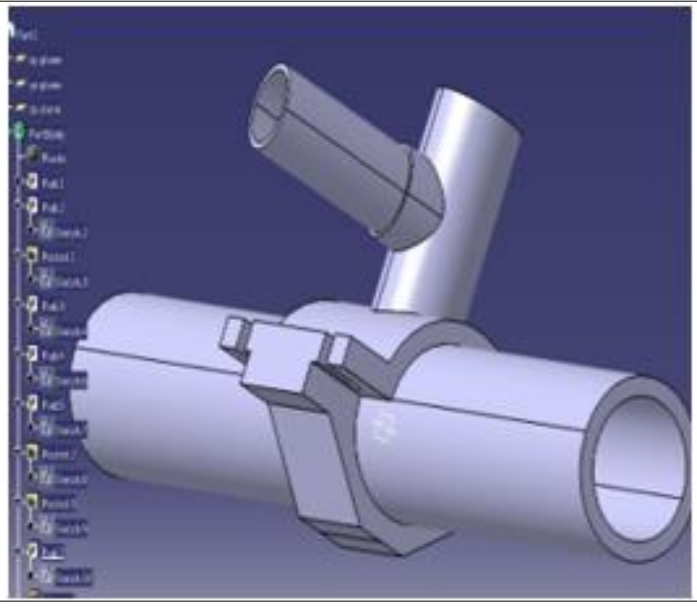

Figure 6. Designing the 3D model of the tapping tee mounted on a polyethylene pipe, by means of Catia software 


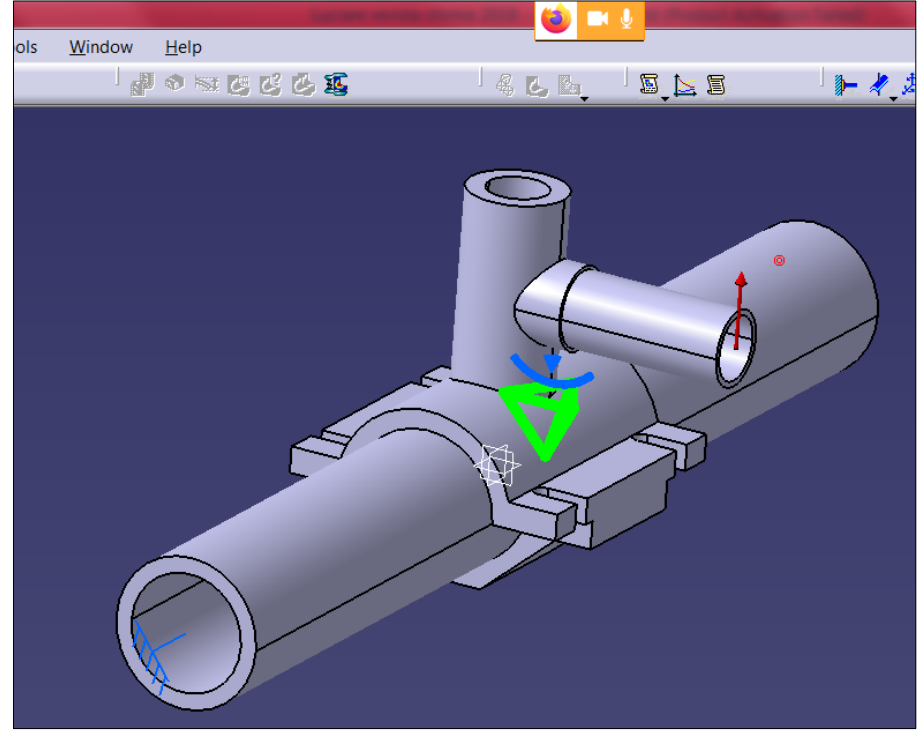

Figure 7. Creating constraints and accidental loads that may occur during operation

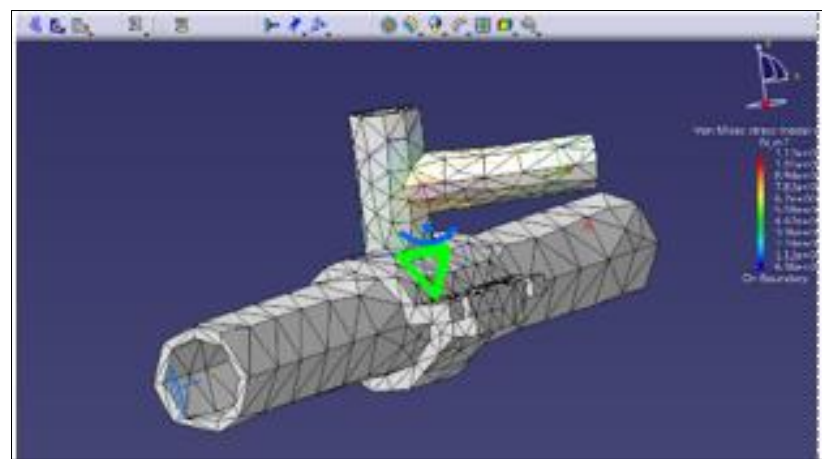

Figure 8. Determining the Von Mises stresses for force $\mathrm{F} \perp \mathrm{Dn} 32 / / \mathrm{Dn} 63$

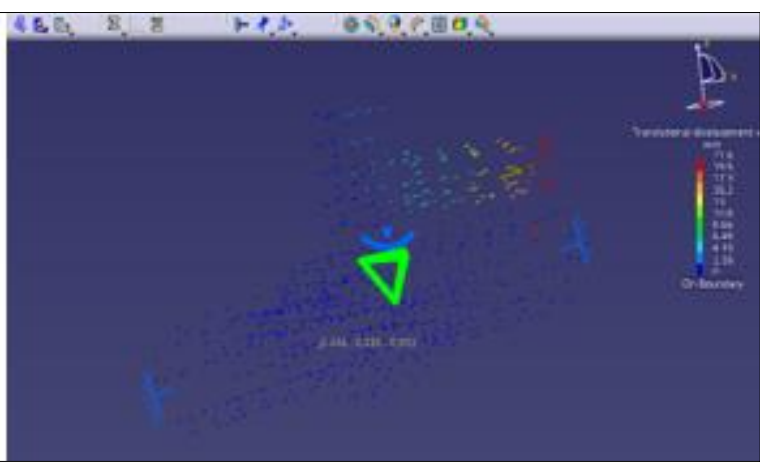

Figure 9. Determining the displacements for force F $\perp$ Dn 32 // Dn63

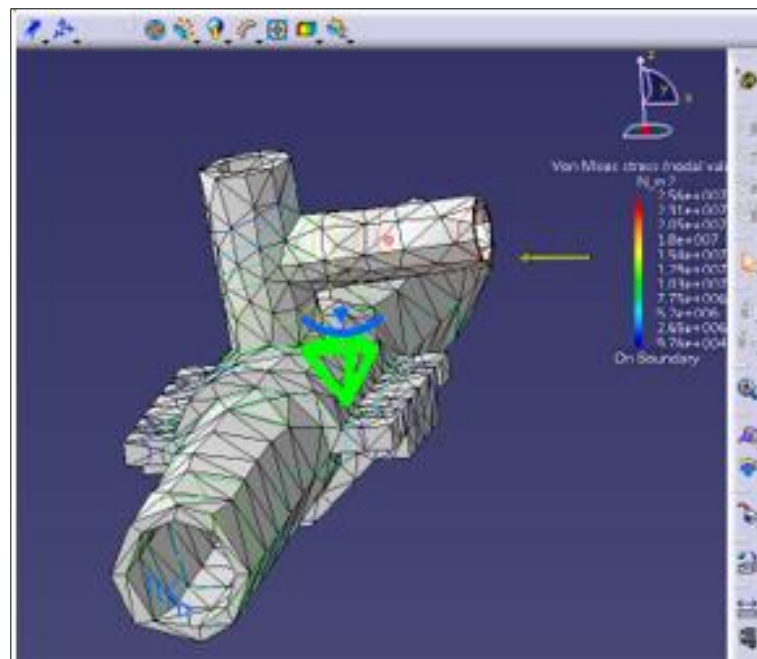

Figure 10. Determining the Von Mises tresses for force $\mathrm{F} \perp \mathrm{Dn} 63 / / \mathrm{Dn} 32$

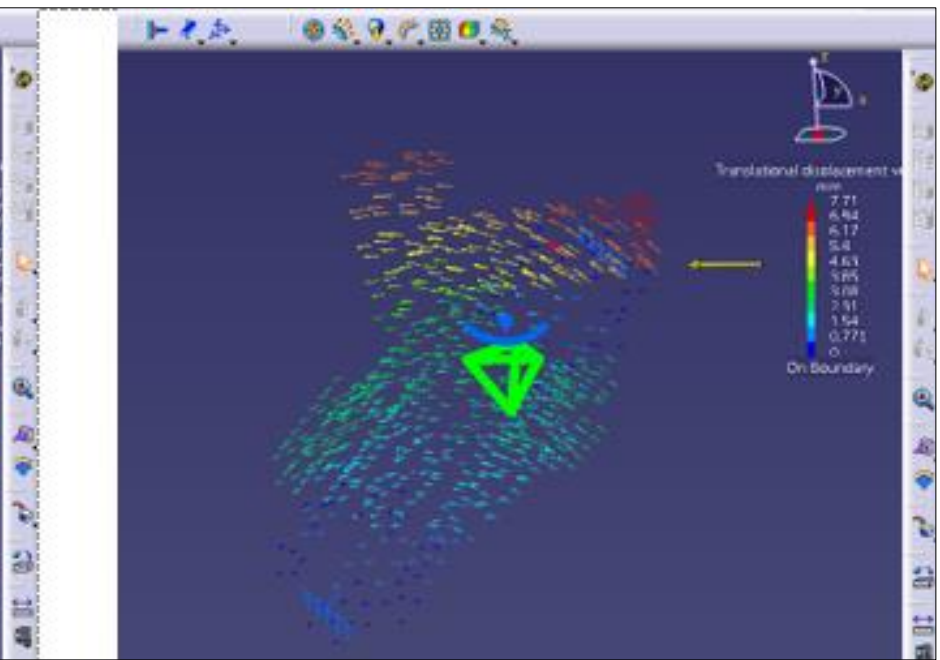

Figure 11. Determining the displacements for force $\mathrm{F} \perp$ Dn $63 / /$ Dn32 


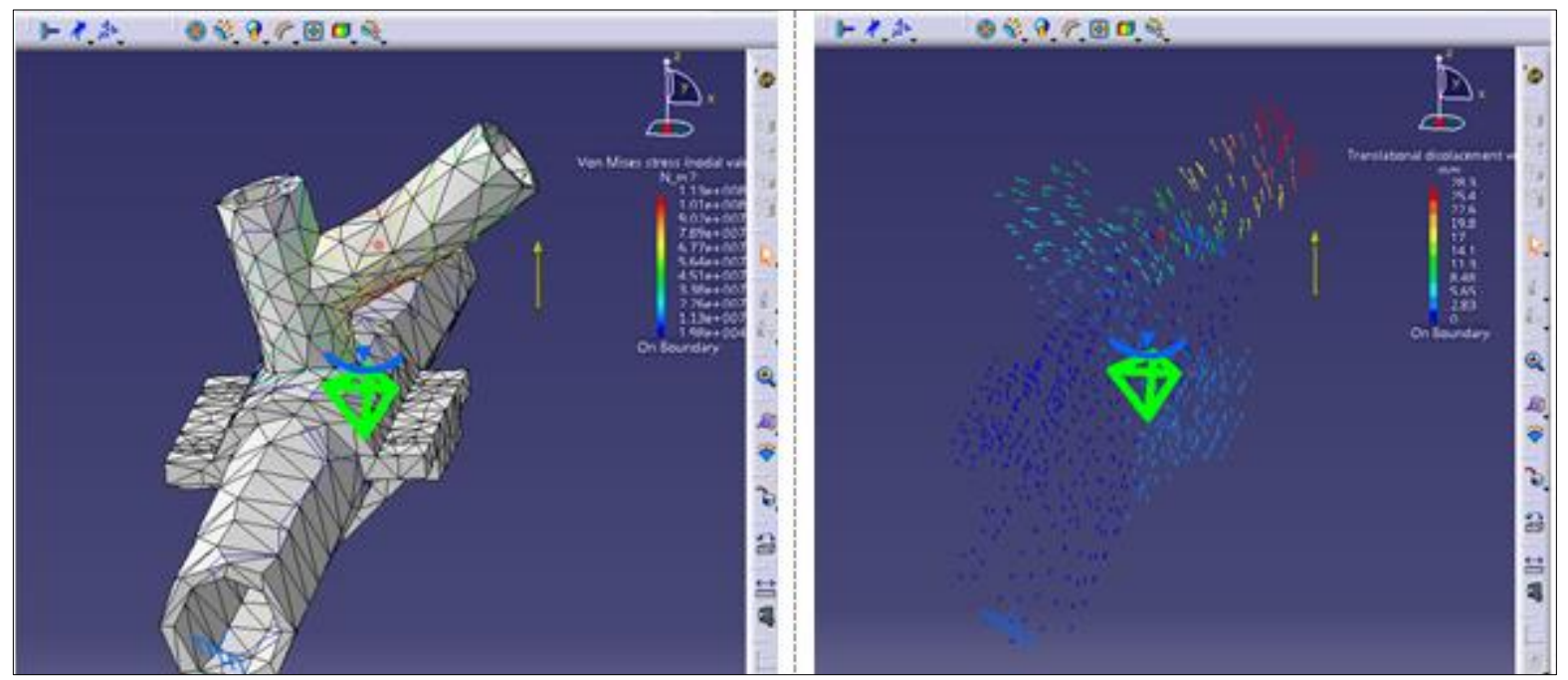

Figure 12. Determining the Von Mises stresses for force $\mathrm{F} \perp \mathrm{Dn} 63 \perp \mathrm{Dn} 32$
Figure 13. Determining the displacements for force $\mathrm{F} \perp \mathrm{Dn} 63 \perp$ Dn32

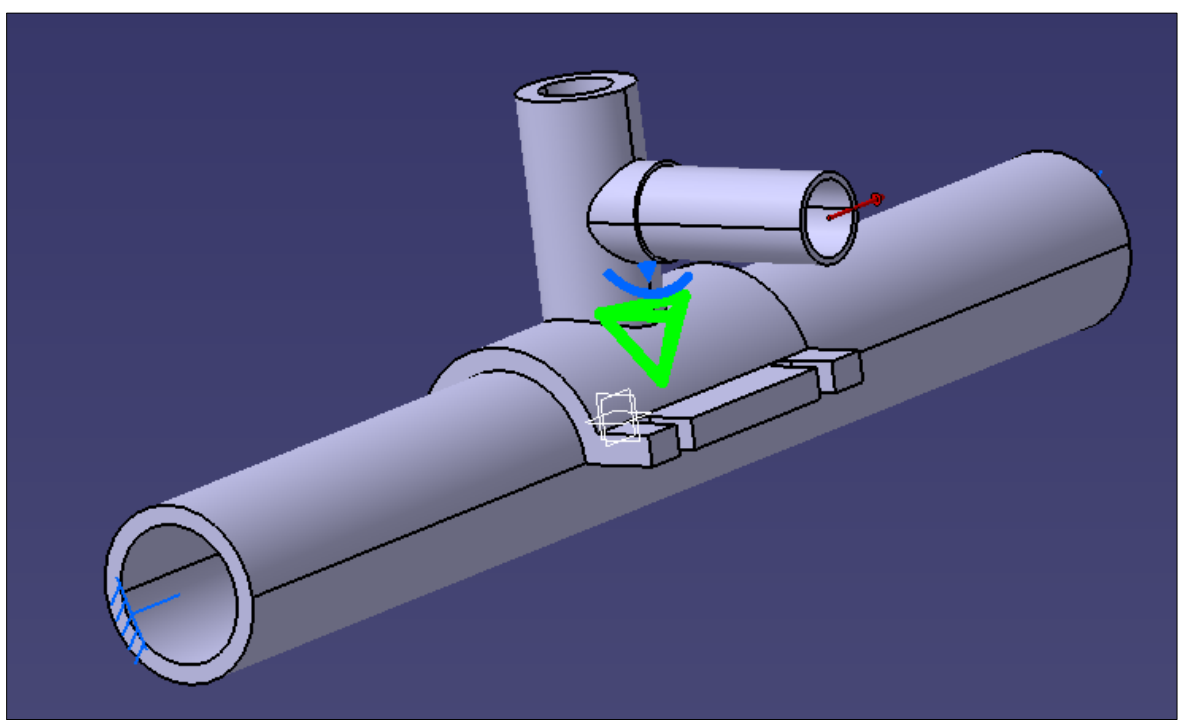

Figure 14. Creating constraints and accidental loads that may occur during operation

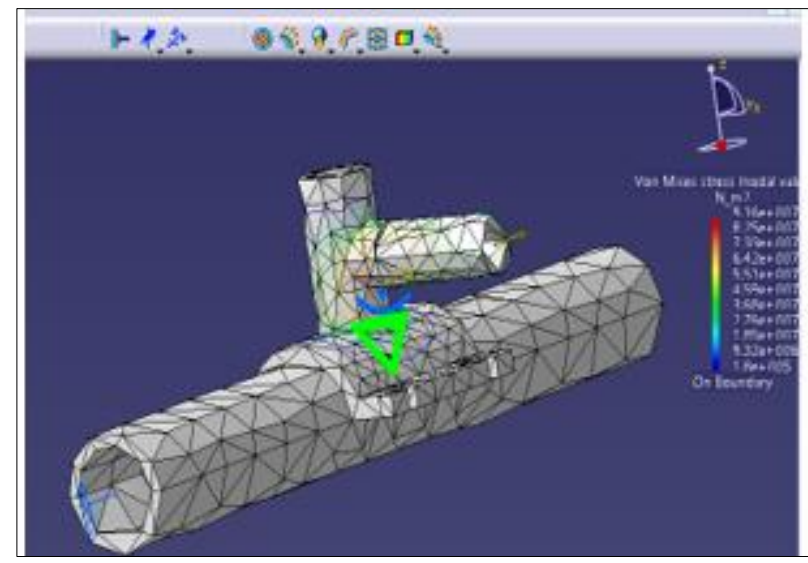

Figure 15. Determining the Von Mises stresses for force $\mathrm{F} \perp$ Dn $32 / /$ Dn63

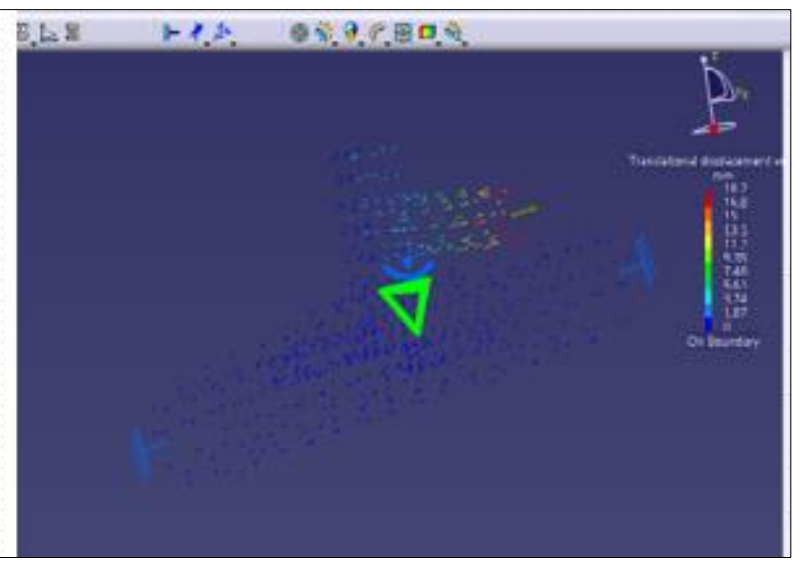

Figure 16. Determining the displacements for force $\mathrm{F} \perp \mathrm{Dn} 32 / / \mathrm{Dn} 63$ 


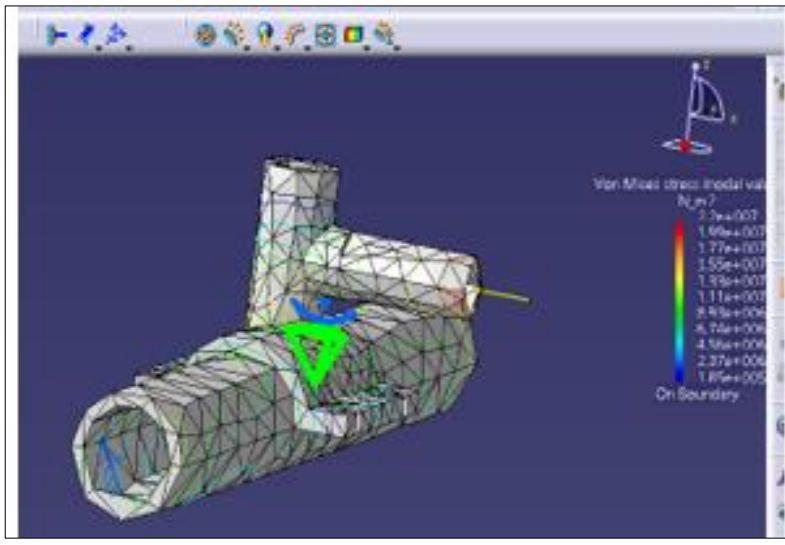

Figure 17. Determining the Von Mises stresses for force $\mathrm{F} \perp \mathrm{Dn} 63 / / \mathrm{Dn} 32$

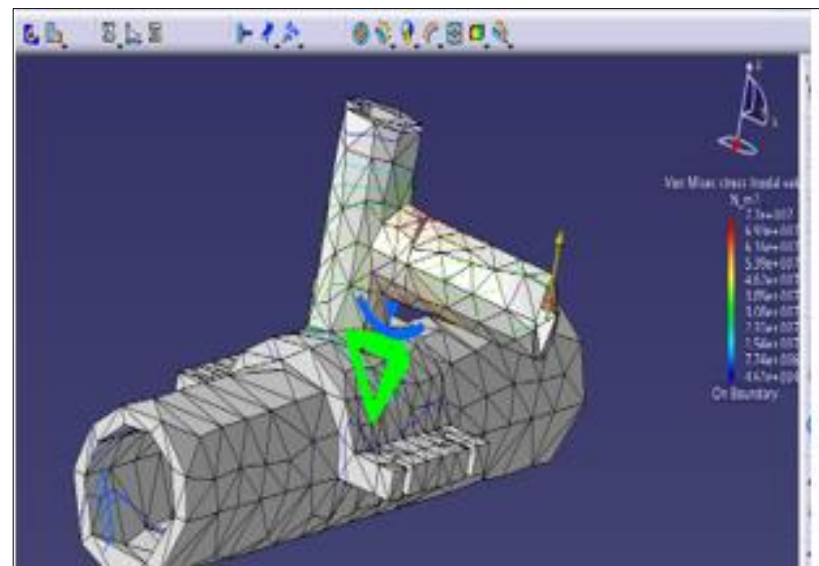

Figure 19. Determining the Von Mises stresses for force $F \perp$ Dn $63 \perp$ Dn32

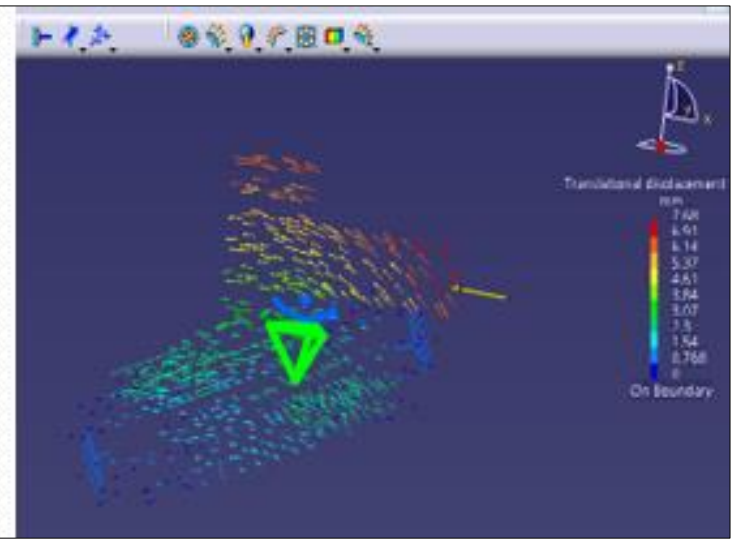

Figure 18. Determining the displacements for force $\mathrm{F} \perp \mathrm{Dn} 63 / / \mathrm{Dn} 32$

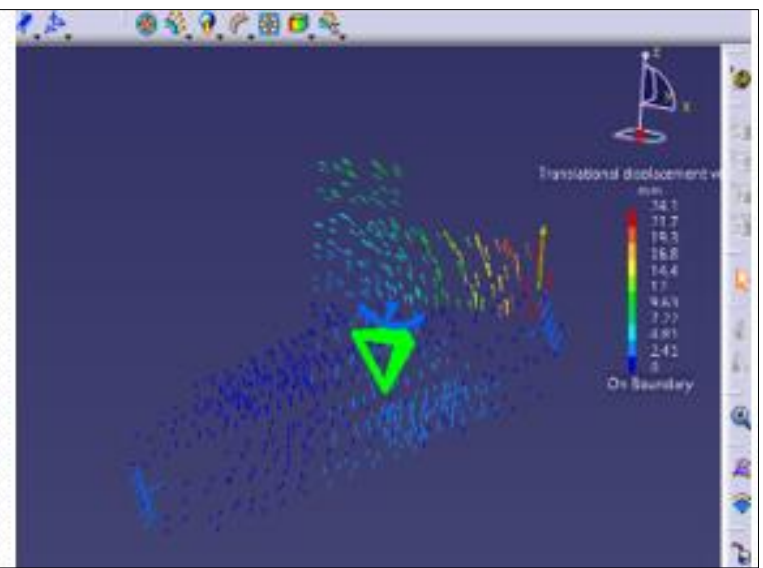

Figure 20. Determining the displacements for force $\mathrm{F} \perp \mathrm{Dn} 63 \perp \mathrm{Dn} 32$

Table 2. Results obtained for the stresses caused by force F likely to occur in practice

\begin{tabular}{|c|c|c|c|}
\hline & Force $\mathrm{F}=5000[\mathrm{~N}]$ & $\begin{array}{c}\text { Von Mises Stress } \\
{[\mathrm{MPa}]}\end{array}$ & Displacement $[\mathrm{mm}]$ \\
\hline \multirow{3}{*}{ Tapping tee } & $\mathrm{F} \perp \mathrm{Dn} 32 / / \mathrm{Dn} 63$ & $112 \mathrm{Mpa}$ & 21.6 \\
\hline & $\mathrm{F} \perp \mathrm{Dn} 63 / / \mathrm{Dn} 32$ & 25.6 & 7.71 \\
\hline & $\mathrm{F} \perp \mathrm{Dn} 63 \perp \mathrm{Dn} 32$ & 113 & 28.3 \\
\hline \multirow{3}{*}{ Branch saddle tee } & $\mathrm{F} \perp$ Dn $32 / /$ Dn63 & 91.6 & 18.7 \\
\hline & $\mathrm{F} \perp$ Dn $63 / /$ Dn32 & 22 & 7.68 \\
\hline & $\mathrm{F} \perp \mathrm{Dn} 63 \perp \mathrm{Dn} 32$ & 77 & 24.1 \\
\hline
\end{tabular}

A difference in rigidity can be observed when the fixing clamp is missing, but also a difference in displacements in the area of the Dn 32 diameter.

\subsection{Determination of the polyethylene behavior and the temperature distribution in the poly- ethylene fittings and pipes during the welding process}

The following equipment was used to perform the study: 1. A machine for welding polyethylene called Sbox, produced by Fusion company from England, capable to weld polyethylene fittings of diameters of maximum $180 \mathrm{~mm}$ and allowing us to observe the soldering cycle [3].

When the cycle is not done correctly, the machine records the error and registers it in the welding protocol; 2. State-of-the-art camera ThermoVision A320 used for recording the temperatures both on a wider surface and on a punctual one; 3 . Software for recording the values measured with the thermal 
camera, providing an overview of the situation or insight on a specific detail. 4. The soldering assembly consisting of the PE 100 SDR11 high density polyethylene pipe DN 32, 63, 90, 110 in diameter employed in the distribution of the natural gas and branch tees made of polyethylene, 32, 63, 90 and 110 $\mathrm{mm}$ in size.

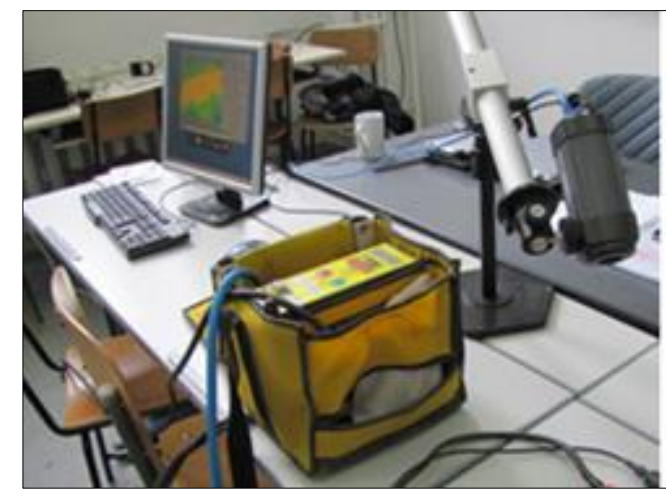

Figure 21. Welding and temperature measuring assembly

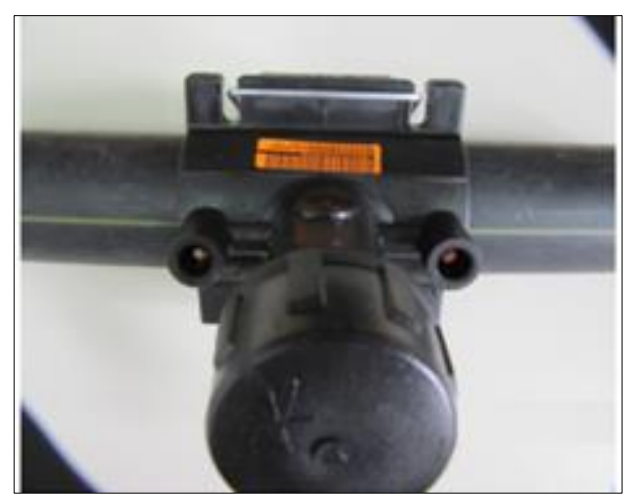

Figure 22. Welding the polyethylene tees to the PE 100 SDR 11 pipe Dn 63 in diameter

The welding technology is observed and only certified tools and machines are used. The Dn 32, 63, 90 and $110 \mathrm{~mm}$ pipe was marked and the coating removed on the surface where the weld will be applied. A metallic scraper was used and then the welding area was etched with a special etching solution. The electrofusion tees Dn 32, 63, 90 and $110 \mathrm{~mm}$ in diameter were set and the welding was ready to start.

Three tests were carried out on the Sbox polyethylene welding machine. The ambient temperature was 22 degrees Celsius. The voltage was automatically adjusted and the welding temperature was progressively increased. This aspect can be observed in the following pictures taken during the measurements [10].

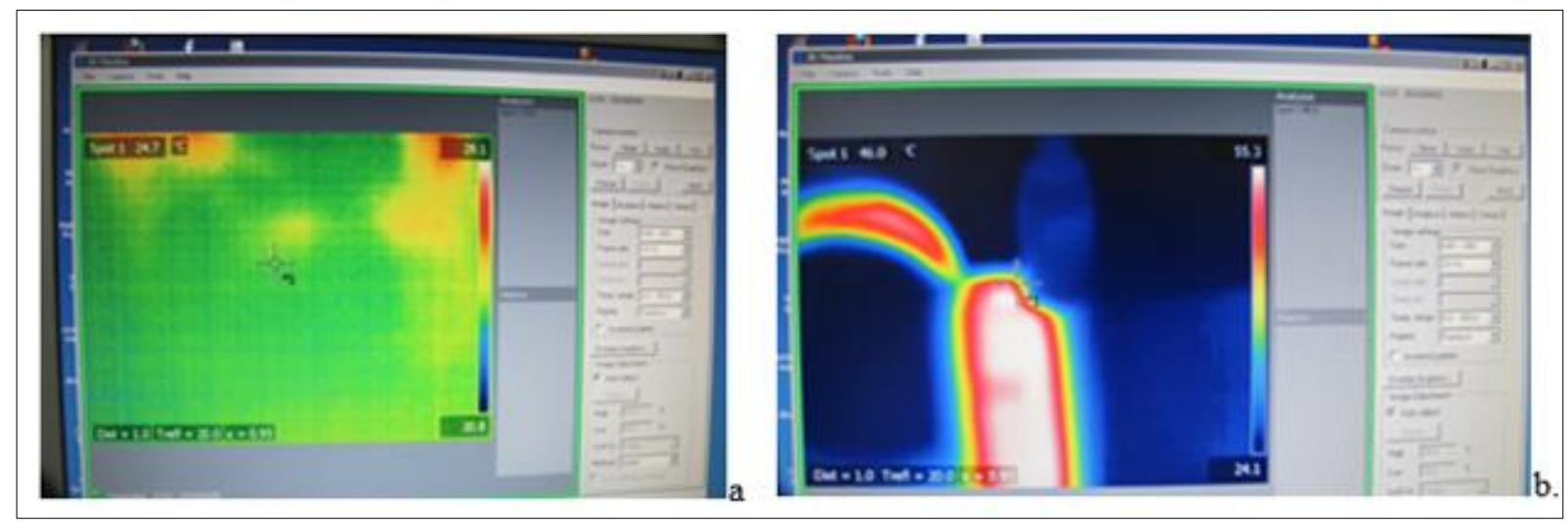

Figure 23. The temperature increase in the welding stages for the DN 63 diameter: a. Initial stage, b. Intermediate stage, when the weld was conducted under appropriate working conditions 


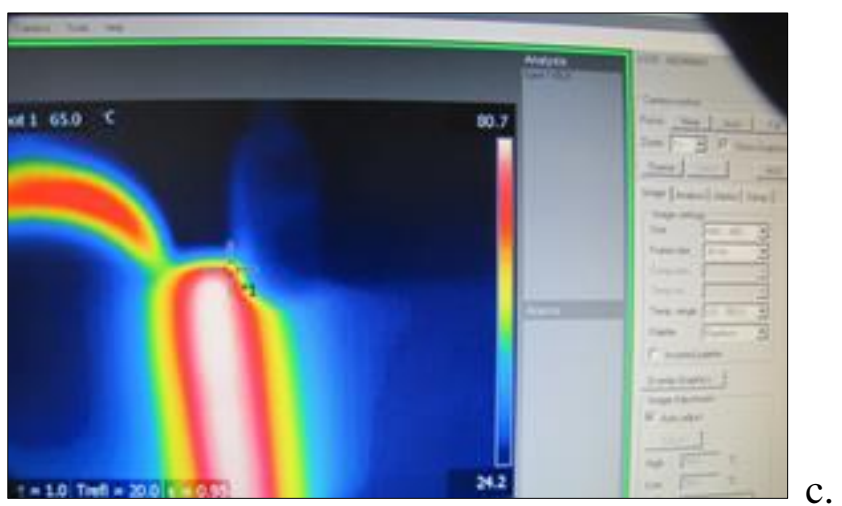

Figure 24. The temperature increase in the welding stages for the DN 63 diameter: a. Initial stage, b. Intermediate stage, when the weld was conducted under appropriate working conditions, c. Final stage, when the weld was conducted under appropriate working conditions

After measuring the temperature during the welding process, we have noticed that: the time required to weld the Dn 63 fitting is $35 \mathrm{~s}$. The welding machine automatically sets the time, upon receiving the information from the fitting and making this adjustment automatically. The duration required for the temperature to increase and stabilize is shown in Figure 25.

Table 3. Temperature distribution when welding a Dn $63-32$ tee

\begin{tabular}{|c|c|c|c|c|c|c|c|c|c|c|c|c|c|c|c|c|}
\hline \multicolumn{10}{|c|}{ Branch Tee Diameter Dn 63-32 } \\
\hline $\begin{array}{c}\text { Time } \\
{[\mathrm{s}]}\end{array}$ & 0 & 20 & 40 & 60 & 80 & 100 & 120 & 140 & 160 & 180 & 200 & 220 & 240 & 260 & 280 & 300 \\
\hline $\begin{array}{c}\text { Temp } \\
{\left[{ }^{\circ} \mathrm{C}\right]}\end{array}$ & 0 & 29.1 & 32.9 & 35.4 & 39.6 & 47.2 & 53.6 & 58.4 & 63.2 & 66.9 & 68.1 & 71.4 & 74.4 & 79.8 & 80.6 & 80.9 \\
\hline
\end{tabular}

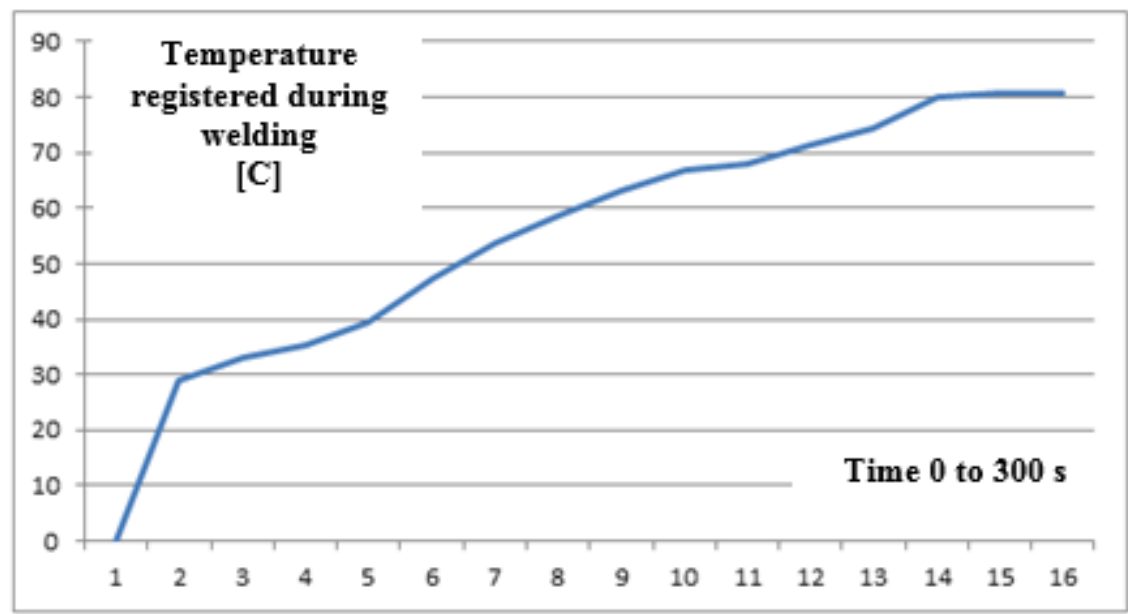

Figure 25. Variation of the temperature in the welding area

\subsection{Mechanical Tests}

The machine used for the conduct of the tests was the Instron 4303 testing machine. The universal traction, compression and buckling testing machine Instron 4303 is a universal testing tool presented in Figure 26a, 26b.

The machine can be loaded with maximum $25 \mathrm{kN}$. It is commanded through the IEEE-488 interface and it uses the specialized Material Testing System series IX software. This testing tool is able to control the velocity of the mobile crosshead. It is $0.5 \%$ accurate and it can register the force with a class ASME 4-E or DIN 51221 Class 1 precision. The control system of the mobile head makes possible to program the velocity of the moving crosshead and ensures the control of the mobile head's position.

The results of the tests are specific to the types of tests for which the machine was designed. Loads, displacements, stresses, specific strains and energies are measured. The results appear as instantaneous values of what it is tested, and upon completion of the test, they appear as peak values or they are recorded in the points set by the user. 


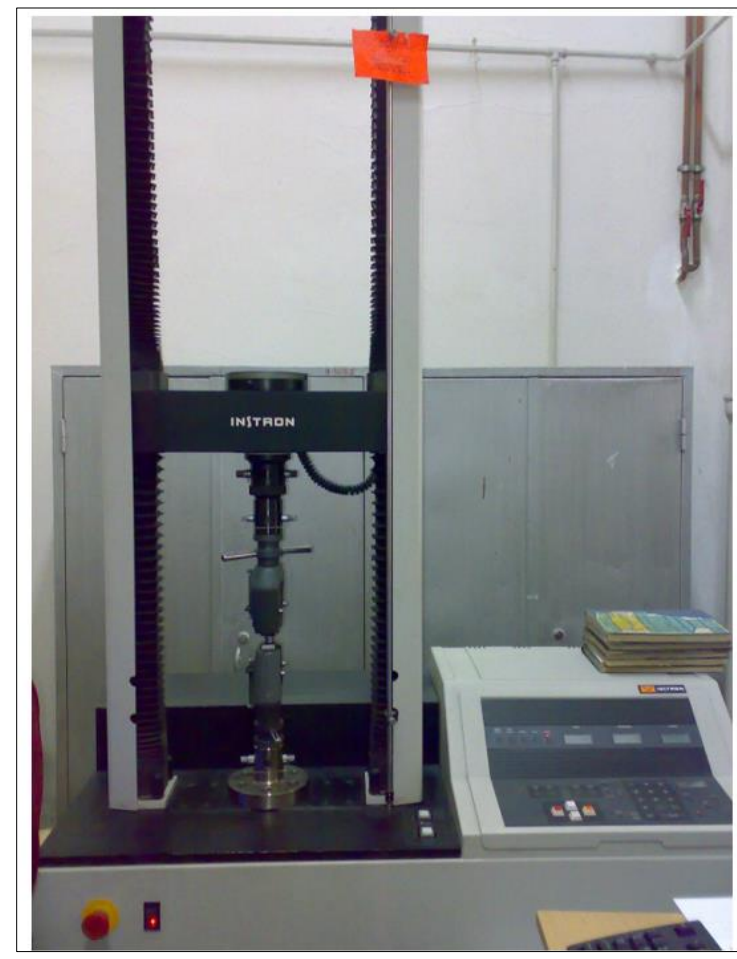

Figure 26a. Machine for testing tensile, compression and Buckling strength Instron 4303

The Instron machine is fitted with a switch (1) which controls the power supply. To make sure that no accidental startups occur, there is a mushroom-headed button (2) on the machine and two clamps to fasten the two grips: (3) the fixed grip and (4) the mobile grip. The moving crosshead (6) travels vertically on the ball screws (8) and it is assembled on the fixed frame (16). The protective covers (9) provide protection against hitting, dust and possible splinters.

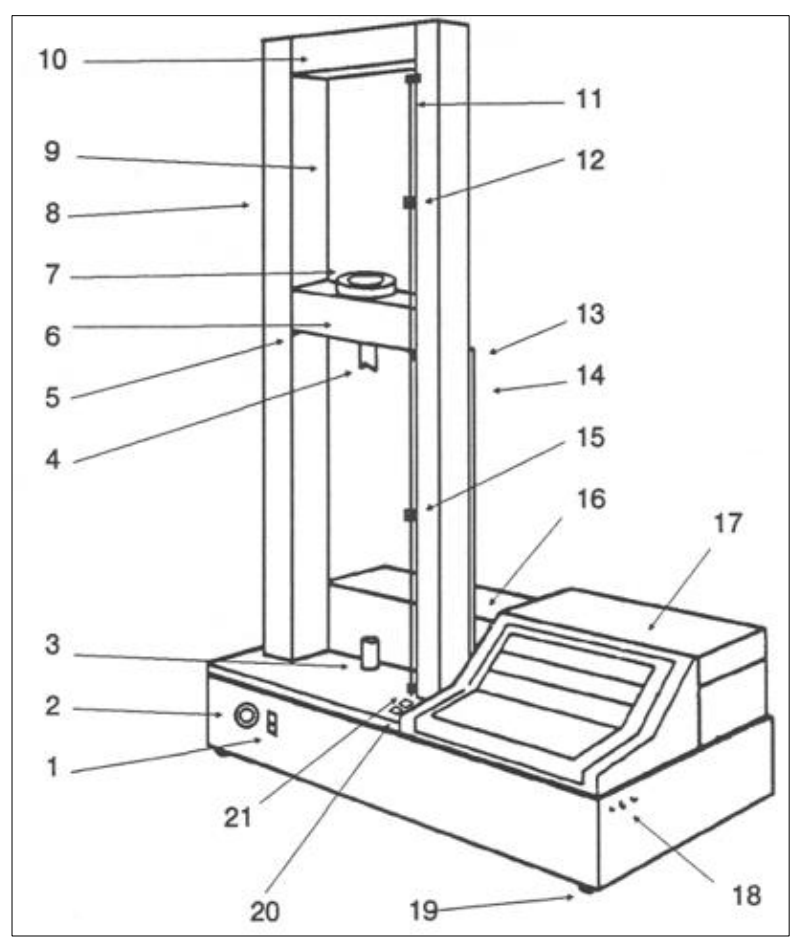

Figure 26b. Machine for testing tensile, compression and buckling strength INSTRON 4303 
The fixed crosshead is located at the top of the machine (10) and fastens the frame. The moving crosshead is provided with a transducer which measures the force (7) and also with a ring which limits the force that the machine is loaded with at maximum $25 \mathrm{kN}$ (5). There are two rods parallel to the two columns of the fixed frame. There are two limit rings at their end which prevent the moving crosshead from hitting the fixed crosshead (11) and the lower part of the fixed frame (21). There are other two mobile limit rings on these two rods. Their purpose is to limit the working area depending on the size of the work stroke $(12,15)$. The transducers which measure the displacements (13) and the connectors which transfer the data received from the transducers to the measuring system (14) are assembled on the right column of the frame. The Instron 4303 machine has a console (17) used for resetting the movement, the capacity of the load and the velocity of the moving crosshead. The console also connects the IEEE interface to the computer. In order to avoid an accidental startup especially during transport, the console is provided with a locking system (18). The machine is set on four supporting legs (19) to level its position. To make sure there are no measurement errors, the machine must be parallel to the ground. The moving crosshead ascends and descends quickly so that the grips could be correctly positioned, when the two buttons next to the work console are pressed.

The data generated by the test can be plotted directly in the force-displacement coordinates after which they are generally converted into stress-strain coordinates.

The stages of the test are as follows:

- we developed 10 specimens;

- the INSTRON testing machine's own code developed a testing method - MATERIAL TESTING SYSTEM.

Figures 26 show the test specimens and the testing methodology used on the INSTRON 4303 machine.

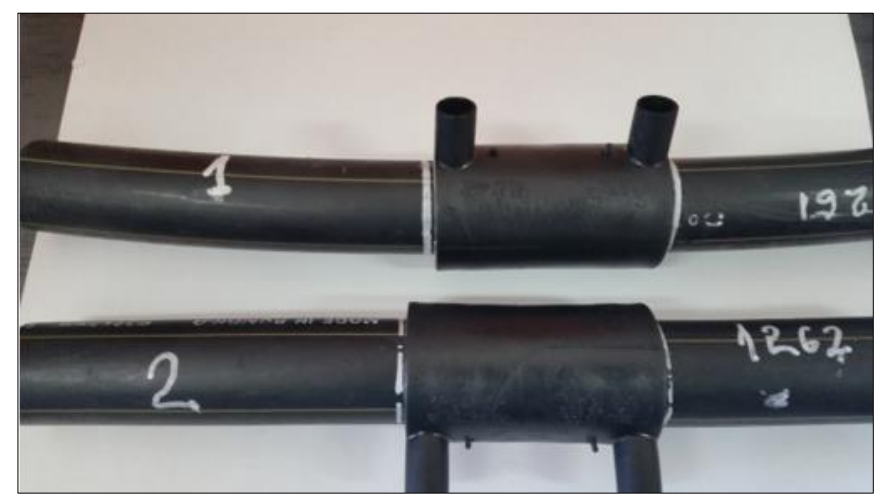

Figure 27. Specimens used for the testing

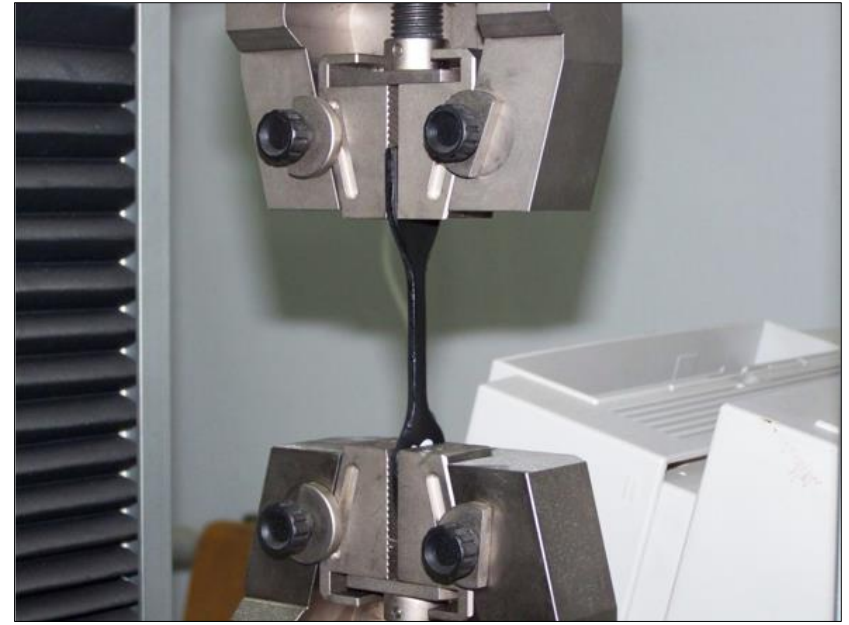

Figure 28. Fastening the pipe in the grips of the testing machine 
Table 4. Experimental results for $\Phi 63$ x 5.8 pipe made of PE 100

\begin{tabular}{|c|c|c|c|c|c|c|c|c|c|}
\hline No. & $\begin{array}{l}\text { Specimen } \\
\text { width }\end{array}$ & $\begin{array}{l}\text { Specimen } \\
\text { thickness }\end{array}$ & $\begin{array}{c}\text { Cross } \\
\text { section area }\end{array}$ & $\begin{array}{c}\text { Specimen } \\
\text { length }\end{array}$ & Test speed & $\begin{array}{l}\text { Maximum } \\
\text { force }\end{array}$ & $\begin{array}{c}\text { Fracture } \\
\text { force }\end{array}$ & $\begin{array}{l}\text { Maximum } \\
\text { elongation }\end{array}$ & $\begin{array}{c}\text { Maximum } \\
\text { Stress }\end{array}$ \\
\hline & $\begin{array}{c}\mathbf{B} \\
{[\mathrm{mm}]}\end{array}$ & $\begin{array}{c}\mathbf{h} \\
{[\mathrm{mm}]}\end{array}$ & $\begin{array}{c}\mathbf{S}_{\mathbf{0}} \\
{\left[\mathrm{mm}^{2}\right]}\end{array}$ & $\begin{array}{c}\mathbf{L} \\
{[\mathrm{mm}]}\end{array}$ & $\begin{array}{c}\mathbf{V} \\
{[\mathrm{mm} / \mathrm{min}]}\end{array}$ & $\begin{array}{l}\mathbf{F}_{\max } \\
{[\mathbf{N}]}\end{array}$ & $\begin{array}{c}\mathbf{F r}_{\mathbf{r}} \\
{[\mathbf{N}]}\end{array}$ & $\begin{array}{l}\Delta \mathbf{L}_{\max } \\
{[\mathrm{mm}]}\end{array}$ & $\begin{array}{c}\sigma_{\max } \\
{[\mathrm{MPa}]}\end{array}$ \\
\hline $\mathbf{0}$ & 1 & 2 & 3 & 4 & 5 & 6 & 7 & 8 & 9 \\
\hline 1. & 6.2 & 5.8 & 18.6 & 100 & 100 & 388.2 & 377.4 & 265.5 & 20.9 \\
\hline 2. & 6.4 & 5.8 & 19.2 & 100 & 100 & 444.8 & 442.1 & 281.2 & 23.2 \\
\hline 3. & 6.4 & 5.8 & 19.8 & 100 & 100 & 432.3 & 423.2 & 272.2 & 21.8 \\
\hline 4. & 6.3 & 5.8 & 18.9 & 100 & 100 & 442.1 & 439.5 & 292.3 & 23.4 \\
\hline 5. & 6.4 & 5.8 & 19.8 & 100 & 100 & 434.1 & 431.4 & 284.8 & 21.9 \\
\hline \multicolumn{6}{|c|}{ Arithmetic mean $\left(\mathrm{x}_{\mathrm{med}}\right)$} & 428.3 & 422.7 & 279.2 & 22.2 \\
\hline \multicolumn{6}{|c|}{ Mean square deviation (s) } & 23.0 & 26.4 & 10.5 & 1.05 \\
\hline \multicolumn{6}{|c|}{ Coefficient of variation $(\mathrm{CoV})$} & 5.38 & 6.24 & 3.77 & 4.70 \\
\hline
\end{tabular}

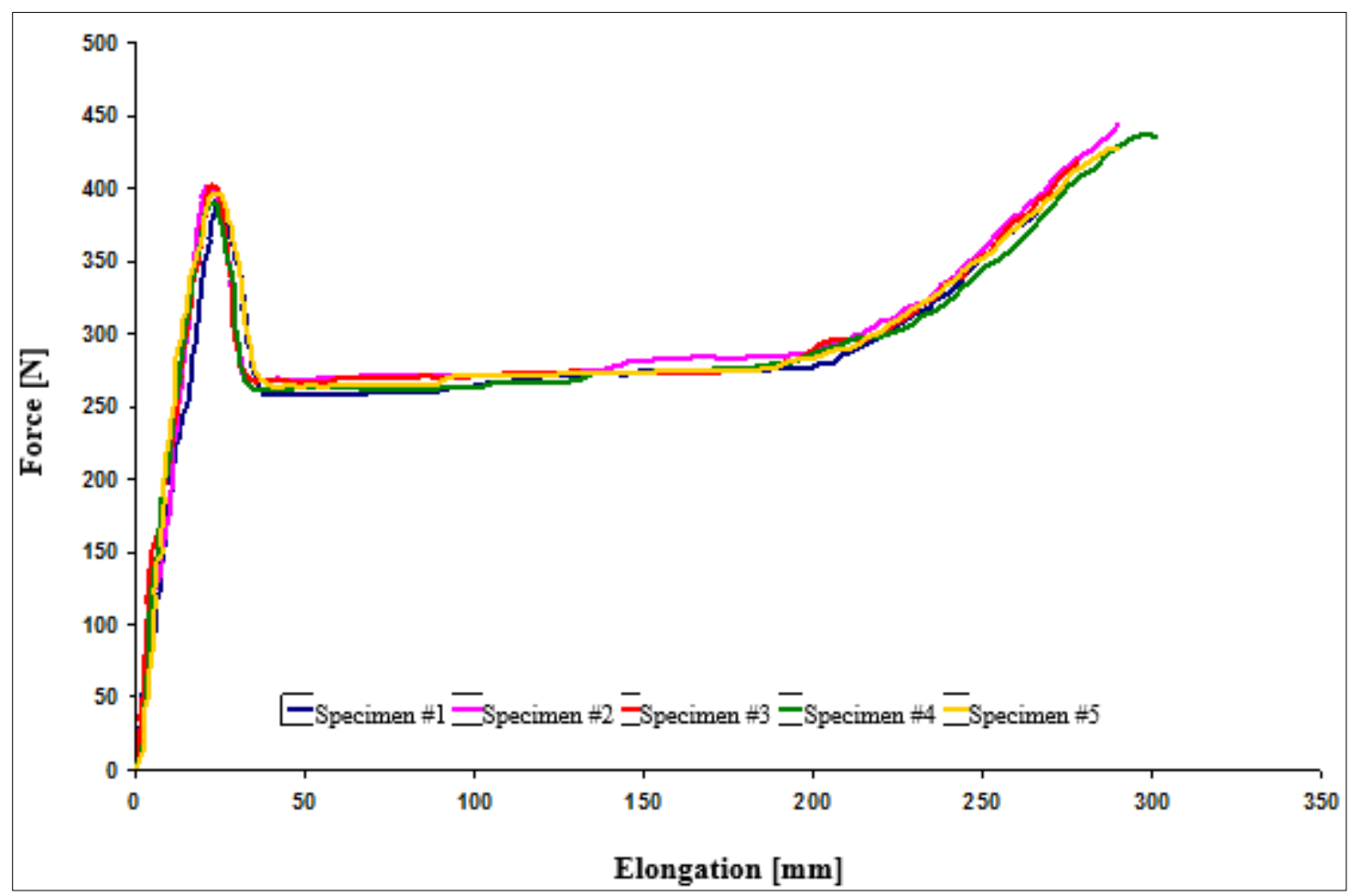

Figure 29. Force-elongation specific curves for a pipe of size

$\Phi 63$ x 5.8 made of PE 100

\subsection{Determining the longitudinal elastic modulus}

The characteristic curves of stress and strain for the tested specimens for which we presented the force-deformation characteristic curves in the previous paragraph were also plotted and the longitudinal elastic modulus was determined for each case.

The next figures show the curves of stress and specific strain for the pipes made of polyethylene $\Phi 63$ $\mathrm{x} 5.8$ in size.

These characteristic curves facilitated the calculation of the values of the longitudinal elastic modulus. The obtained results are shown in the table below. We developed a statistical analysis (similar to that for experimentally determining the data for each type of pipe), and established the arithmetic mean of these values, as well as their mean square deviation, and the coefficient of variation. 


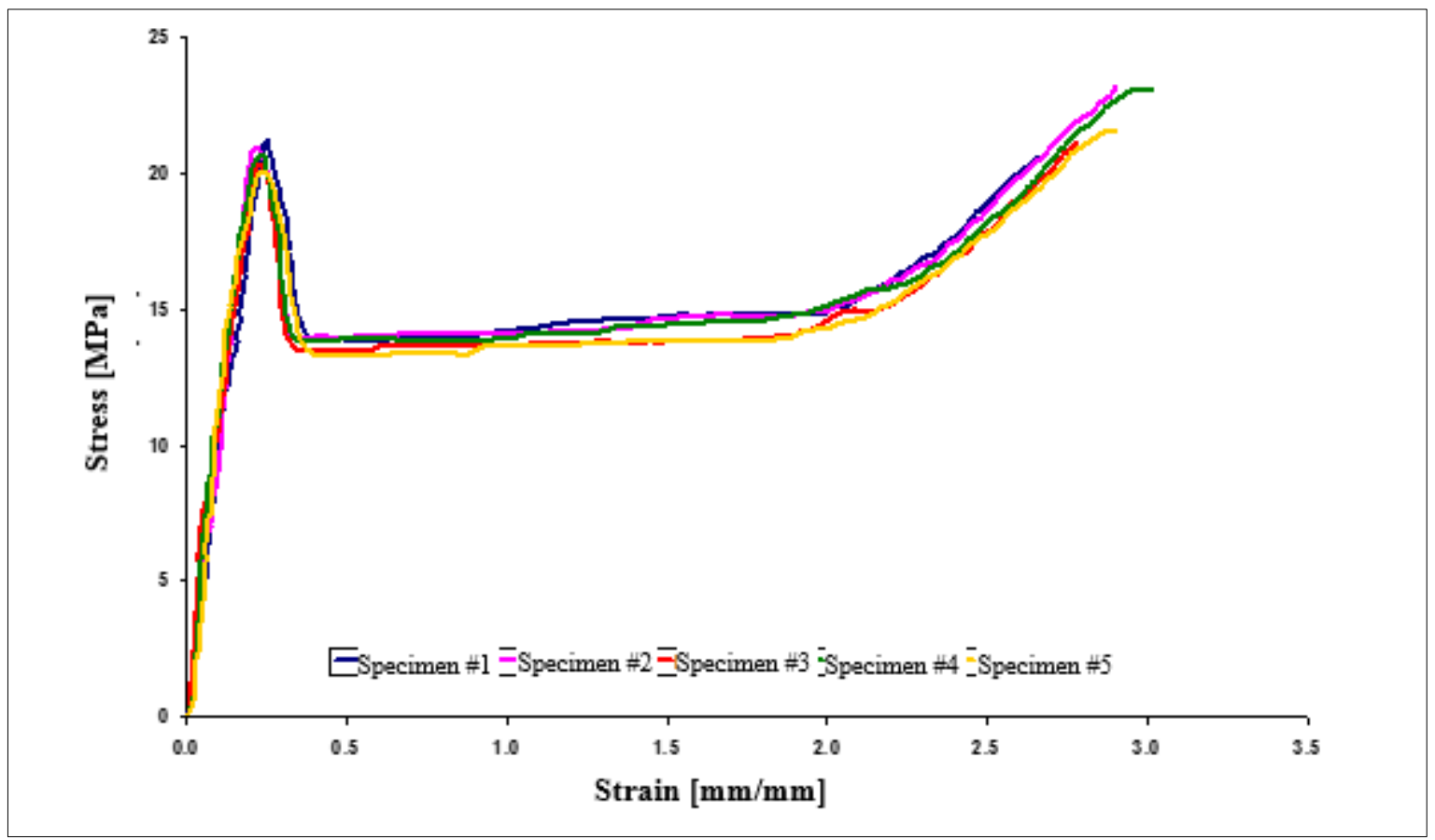

Figure 30. Stress-strain characteristic curves for PE 100 pipe specimens $\Phi 63$ x 5.8 in size

Table 5. The elastic modulus for a PE 100 pipe $\Phi 63$ x 5.8 in size experimentally determined

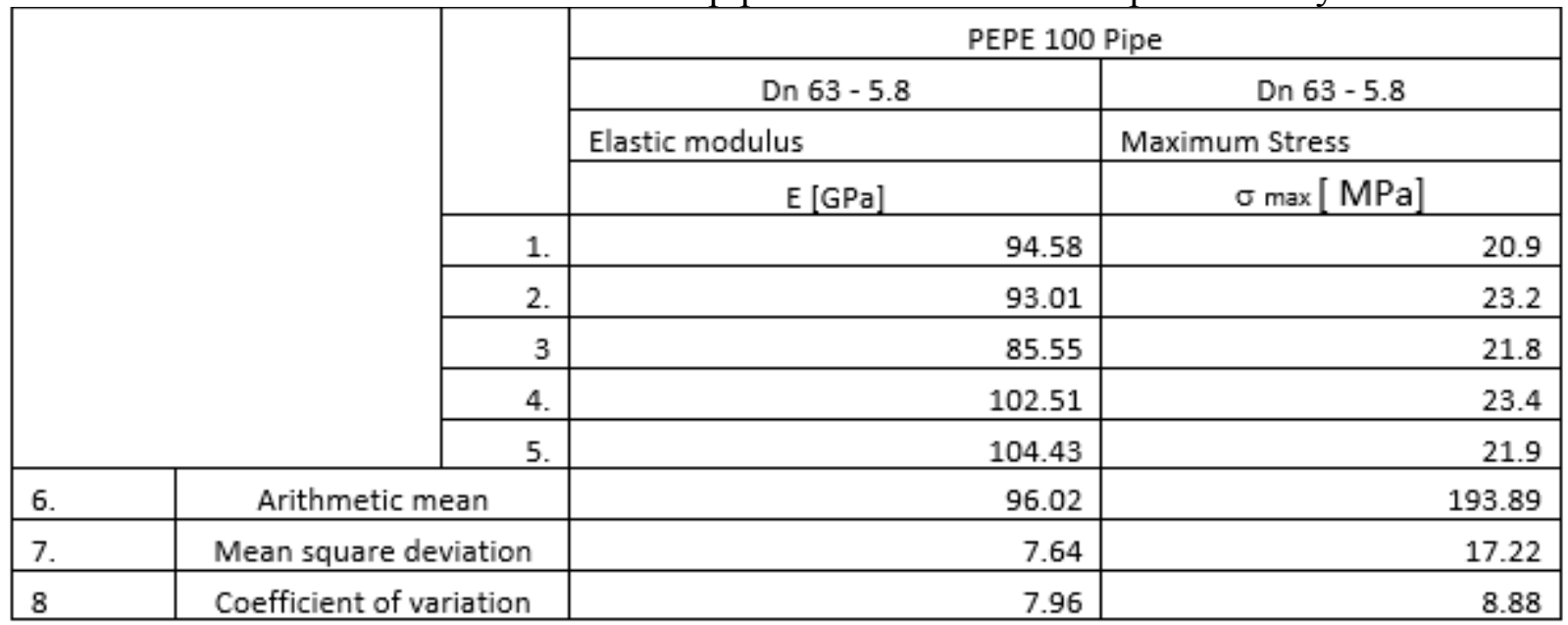

These experimental data, in particular the stress-strain characteristic curves and the longitudinal elastic modulus will be used in the finite element analyses (simulations).

\section{Conclusions}

The following conclusions have been drawn from conducting the above mentioned study:

- it is recommended to approach the suggested topic and to disseminate the results of a study on the behavior of the polyethylene pipes when subjected to accidental mechanical factors;

- the questionnaire enquiry highlights the areas sensitive to problems occurring in the operation of the polyethylene pipes;

- the analysis models of $63 \mathrm{~mm}$ diameter were designed for the tapping tee equipped with a welding device;

- these models which actually have the features of the polyethylene were subjected to different stresses in accordance with the testing scheme; 
- the temperature distribution in the pipe and in the branch tee was observed by means of the thermal camera;

- the values obtained after stressing the two branch tees are different because the metal clamp causes a different rigidity and blocks the deformation of the material, according to the values obtained by the finite elements study.

The approach of the present topic led to the suggestion to extend this study to parts of other diameters as well and to take into consideration the possibility of a PE 100 polyethylene pipe being mechanically stressed by different regular or irregular shaped bodies.

\section{References}

1.AVRIGEAN, E. Studii teoretice si experimentale asupra comportarii mecanice a ansamblurilor sudate de tevi si fitinguri din polietilena de inalta densitate. "Lucian Blaga" University Publishing House, Sibiu. 2015.

2.AVRIGEAN E., GRECU, V. Market research regarding problems in using polyethylene pipe and fittings. Academic Journal of Manufacturing Engineering, vol. 12, Issue 4 / 2014.

3.AVRIGEAN EUGEN, HUNYADI LASZLO (2015): Studies and Researches on the Temperature Fields for Electrofusion Welding the High Density Polyethylene Elbows-Pipes Assemblies. International Conference on Power Electronics and Energy Engineering (PEEE2015) Hong Kong, April 19-20, 2015. 4.AVRIGEAN EUGEN, s.a. (2016): Theoretical and Experimental Determination of the Fracture-Risk Areas on the Electrofusion Socket Made of High Density Polyethylene, Mater. Plast., 53(4), 2016, 718 5.DUSE, D. M., BONDREA, I. Fabricatia integrata de calculator CIM a transmisiilor cardanice. "Lucian Blaga" University Publishing House, Sibiu, 2003 - chapter 3 - Model of a market study on cardan shafts. 6.FILIP, S., AVRIGEAN EUGEN, s.a. (2017): Studies and research on the electrical resistance of the polyethylene insulation used for the chemical protection of the steel pipelines intended for the natural gas distribution. Mater. Plast., 54(1), 2017, 63

7.LUPU, N.I. Conducte din polietilena in sistemele de distributie. "Lucian Blaga" University Publishing House, Sibiu, 2000.

8.OLEKSIK, V., PASCU, A.M. Proiectarea optimala a maşinilor si utilajelor, "Lucian Blaga" University Publishing House, Sibiu, 2007.

9.***SR ISO4437 - 2001. Polyethylene pipes used in buried gaseous fuel distribution networks.

10.STETIU MIRCEA, AVRIGEAN EUGEN, s.a. (2016): Determining the temperature field at welding the polyethylene sockets, Mater. Plast., 53(3), 2016, 470

11.*** Technical book for HDPE pipes and fittings - Valrom Industrie.

12.*** Catalog of products by Fusion Romania 2020

$\overline{\text { Manuscript received: } 17.11 .2020}$ 